\title{
Illusory attitudes and the playful stoic
}

\author{
Michael Ridge ${ }^{1}$ (D)
}

Accepted: 17 December 2020/Published online: 9 January 2021

(C) The Author(s) 2021

\begin{abstract}
What we might usefully call "playing full-stop" and playing games plausibly figure in a well-lived life. Yet there are reasons to worry that the two not only do not naturally go hand in hand, but are in fact deeply opposed. In this essay I investigate the apparent tension between playing full-stop and playing competitive games. I argue that the nature of this tension is easily exaggerated. While there is a psychological tension between simultaneously engaging in earnest competitive game play and playing fullstop, there is no logical contradiction between the two. Somewhat surprisingly, seeing how this tension is best understood teaches us something about the nature of willing an end and the "guise of the good." With a resolution of the apparent tension between playing full-stop and playing competitive games, I turn to the practical worry that playing competitive games is destructive precisely for the very reasons it is opposed to playing full-stop. Here I develop a positive proposal to mitigate the tension between playing full-stop and playing competitive games. This proposal draws on the idea of "striving play" as recently developed by Thi Nguyen and some ideas from classical Stoicism.
\end{abstract}

Keywords Games · Action theory - Guise of the good · Value theory · Play · Competition

Both playing games and what might usefully be called "playing full-stop" plausibly figure in a well-lived life. Playing full-stop is just playing, without thereby necessarily playing anything-a game, a musical instrument, a joke, or whatever. A child frolicking on a grassy hill is a paradigm case of play full-stop without playing

Michael Ridge

mridge@staffmail.ed.ac.uk

1 University of Edinburgh, Edinburgh, Scotland, UK 
a game (etc.). Although distinct and separable, playing full-stop and playing games seem naturally go hand-in-hand. Games provide a framework for structured play. Indeed, one might have thought that combining play full-stop with game play could be more valuable than the sum of the value its parts - a "Moorean" organic unity. Yet, when it comes to competitive games, there are reasons to worry that the two are actually in tension with one another. In this essay I investigate the apparent tension between playing full-stop and playing competitive games. I argue that the nature of this tension, while real, has been exaggerated and misunderstood. I then develop a strategy for mitigating this tension in practice, a strategy which draws on both Thi Nguyen's idea of "striving play" and some insights from the Stoical tradition. Somewhat surprisingly, along the way the development of this strategy reveals something interesting about the age-old debate about whether willing an end must always be "under the guise of the good."

I begin by arguing that the tension between playing competitive games and playing full-stop arises from two sources. First, play full-stop essentially involves an element of spontaneity, whereas playing a competitive game paradigmatically involves following strict rules. Second, play full-stop essentially involves doing something for the fun of it, but playing a competitive game in earnest involves a level of intensity and associated anxiety about the outcome which can detract from fun and enjoyment. I argue that the first of these tensions is highly game-relative and easily exaggerated. The second tension is deeper, but I argue that it too can be resolved. Seeing how this second tension is best understood and can be resolved reveals something interesting about willing an end-that it is possible to will an end and pursue it wholeheartedly without taking that end itself to be good. This stands in stark opposition to at least some formulations of the influential "guise of the good" thesis, defended by Kantians and Platonists. On these views, all action is performed under the guise of the good-where this means taking the end one pursues to be good in some way. This, in turn, reveals something interesting about what Bernard Suits famously called the "lusory attitude," which on his account is partly constitutive of playing a game. A clearer view of the nature of this tension also enables us to see why it is natural to use the same word ('play') to refer both to playing full-stop and playing competitive games.

My proposal for mitigating this second and deeper tension takes as its starting point the idea of "striving play" as developed by Thi Nguyen. I discuss some limitations of Nguyen's approach and develop some ideas from the Stoic tradition as an alternative way of resolving the tension. I argue that the Stoic approach has some of the same advantages as Nguyen's approach but is more psychologically realistic. In effect, the version of Suits' "lusory attitude" would be quite unrealistic for most serious competitors-hence the pun in my title-the "illusory attitude." By contrast, the Stoic approach, while not psychologically easy, is more realistic. The approach I defend promises to maintain a kind of dynamic tension between the seriousness of playing a competitive game in earnest and maintaining a playful attitude. This resolution, in turn, can help meet the normative worry that playing competitive games in earnest is inherently stressful and destructive. A Stoical approach allows us to enjoy the goods of competitive games while remaining playful, and thereby lead more fulfilling, well-rounded lives, or so I argue. 


\section{Playing full-stop and playing competitive games}

Play and competitive games stand in a vexed relationship. We play competitive games, but here 'play' is used as a transitive verb. 'Play' has other transitive uses; one can play the piano, play someone for a fool or play a joke on someone. Plausibly, 'play' is what linguistics call an 'ambitransitive', admitting of both transitive and non-transitive uses. A child frolicking on a grassy hill is playing fullstop even though she is not playing anything (a game, the piano, a joke, etc.). To be clear, when I say that play and competitive games stand in a vexed relationship, I mean play full-stop and playing competitive games stand in a vexed relationship.

The somewhat surprising tension between playing full-stop and playing competitive games raises closely related practical and theoretical issues. The practical issue concerns the way in which this tension can cast doubt on the value of playing competitive games. Insofar as competitive games destroy our more prosocial playful attitude, they can breed antagonism, distrust, workaholism, and other destructive attitudes. The closely related theoretical issue is why we find it natural to speak of playing competitive games if playing full-stop and playing competitive games are opposed. It seems unlikely to be a brute accident that the same word is used in both cases, particularly given that this pattern is cross-linguistically robust.

The tension between playing competitive games and playing full-stop is not hard to discern. Playing a competitive game in earnest is serious business. One sets oneself a goal (checkmate, scoring baskets, etc.) and one works hard to achieve that goal. Intuitively, though, play full-stop is essentially non-serious. Indeed, many definitions characterize it as non-serious. Play is also sometimes taken to be the opposite of work. The image of Garry Kasparov deep in thought during an intense world championship game is not the image of a playful soul. Mark Pesce puts the point this way:

Games are the end of play; even as they seek to encompass play within the magic circle, games direct play away from itself, toward goals and rewards, thus depriving play of its playfulness. We may play games, but we have never done so playfully... where every act has been weighed down with the possibility of loss, play loses its freedom to explore, to mistake and to renew itself. (Pesce 2014: 110)

A similar sentiment is found in this nice quotation from Grandmaster Jonathan Rowson:

Chess is just a game in the way that the heart is just a muscle. (Rowson 2019: 1)

Indeed, some critics of competitive games argue that they tend to pervert our naturally playful and more cooperative nature, turning us into anti-social, compulsive workaholics.

This tension between playing competitive games and playing full-stop is, on reflection, puzzling. On the one hand, the tension between playing full-stop and playing competitive games in earnest (a la Kasparov in my example) is intuitive and 
real. On the other hand, it seems unlikely to be a brute accident that we use 'play' to describe what people are doing when they play competitive games. Granted, there is no semantic entailment from 'playing a game' to 'playing' full-stop, nor does the opposite entailment hold. The example of the child frolicking on the hill illustrates that 'play full-stop' does not entail 'play a game'. Only slightly more controversially, the entailment does not hold in the other direction. A jaded footballer who is just in it for the money still counts as playing football. From the fact that there is no semantic entailment, though, it does not follow that it is a brute accident that we use the word 'play' to characterize gaming. Compare: 'green' is ambiguous as between denoting a colour and indicating that someone is immature or inexperienced at something; here too there is no semantic entailment. Still, it is clearly not an accident that the same word is used in both cases. Moreover, the fact many other languages have a single word with a similar set of meanings in both contexts (e.g. 'Spiel' in German) corroborates the idea that this is no accident. Why, then, do we use the same word in both contexts? We need an explanation of this cross-linguistic phenomenon that adequately accommodates the apparent tension between playing full-stop and playing competitive games in earnest.

Perhaps the explanation is just this: games characteristically involve playing fullstop, even if this is not essential to playing games. On this sort of account, any particular instance of gaming can occur without any accompanying play full-stop, but this is parasitic on a background in which gaming and play full-stop coincide. ${ }^{1}$ A species which never engaged in play full-stop would not play games. Perhaps games provide a scaffolding which builds on more primitive forms of play. A bolder hypothesis is that what makes a given practice constitute a game is that its primary function is to make possible such rule-governed play. ${ }^{2}$ However, the deeper and more ubiquitous the tension between playing full-stop and playing competitive games in earnest, the more dubious this explanation of the cross-linguistic data will look. We therefore need a clearer view of the source, depth and ubiquity of this tension.

In my view this tension has two sources. The first is that competitive games are somehow incompatible with the free-spirited activity and spontaneity associated with play full-stop. Games plausibly are constituted by strict rules, and following strict rules seems incompatible with the carefree attitude of a playful spirit. This idea is elaborated in the context of the professionalization of sport in Johan Huizinga's classic Homo Ludens. Huizinga argues that competitive games (his focus is sports) tend toward regimentation, record-keeping and professionalism, all of which further undermine the "play spirit":

...with the increasing systematization and regimentation of sport, something of the pure play-quality is inevitably lost... The spirit of the professional is no longer the true play-spirit; it is lacking in spontaneity and carelessness. This affects the amateur too, who begins to suffer from an inferiority complex. (Huizinga 1949: 197)

\footnotetext{
1 Compare (Hurka 2019).

2 I defend a view along these lines in Ridge (2019).
} 
A second source of the tension is that there seems to be an essential connection between playing full-stop and doing something for the fun of it. Yet playing a competitive game in earnest seems somehow too intense to be amenable to just having fun. There is too much at stake for earnest competitors for them simply to relax and enjoy the process. Alfie Kohn, in No Contest: The Case Against Competition, seems to be drawing on this source of the tension between competitive games and play full-stop, though he (as many other theorists) puts the point in terms of seriousness:

....most definitions of play do seem to exclude competitive activities...most important, competition is goal-oriented striving par excellence. Novak is quite right to insist that 'play is to be played exactly because it isn't serious; it frees us from seriousness.' Competition, though, is very serious indeed-unavoidably so...competition and play tug in two different directions. If you are trying to win, you are not engaged in true play. (Kohn 1986: 82-83)

This line of thought is not uncommon. Kohn cites several other theorists who offer similar arguments.

It is not entirely clear from the text, but Kohn (and some of those he cites) seem to think that there is some logical contradiction between playing full-stop and playing a competitive game. That, though, seems like the wrong sort of tension. I suspect it is easy to get misled into thinking the tension amounts to a logical contradiction by framing the issue in terms of seriousness. One problem is that 'seriousness' is open to multiple ambiguities. Perhaps play is not serious in the sense of having no clear further function or purpose beyond itself, while striving to win a game is serious in the sense of involving intense concentration. Since one can intensely concentrate on a goal which is entirely internal to an activity (e.g. winning the game), there need be no tension between being unserious in the former sense but serious in the latter. More generally, perhaps 'serious' expresses a cluster concept, and the claim that play is not serious picks up on certain elements of the cluster, while the claim that trying to win is serious picks up on other elements of the cluster. $^{3}$

In my view, the tension is psychological rather than logical, and arises out of the earnest competitor's tendency to be so intensely focused on winning. It is worth noting that on what is arguably the most influential account of what it is to play a competitive game, trying to win is essential to playing the game. Here I have in mind Bernard Suits' classic definition of 'play a game' in The Grasshopper. On Suits' view, playing a game has three basic elements: (1) the prelusory goal, which is a goal which can be understood independently of playing the game, (2) the constitutive rules, which must make it more difficult to achieve the prelusory goal, and (3) the lusory attitude, which is a matter of accepting the constitutive rules because of the activity they make possible. The lusory goal is simply the prelusory goal achieved in ways permitted by the constitutive rules. To play a game is to adopt

\footnotetext{
3 Thanks to an anonymous referee for suggesting this as a possible explanation of why the dilemma is only apparent.
} 
the lusory attitude and seek the prelusory goal only in ways permitted by the constitutive rules. For example, to play golf is to seek the prelusory goal (getting the ball in the cup), but only in ways compatible with the constitutive rules (one must use golf clubs as they are intended to be used), where one accepts the rules just because they make this sort of activity possible. Oversimplifying slightly, playing a game is "the voluntary attempt to overcome unnecessary obstacles." (Suits 1978: 41)

An obvious corollary is that insofar as someone is not trying to win he is not really playing the game. Suits follows his argument where it leads and explicitly embraces this upshot, arguing that a "trifler" who pretends to be serious about playing a given game but makes no effort to win is not really playing the game. I am not convinced, and I think we can preserve what is insightful in Suits' definition without having to say that there is no useful sense in which a trifler is playing the game. However, this nuance does not matter here. At least in a paradigm case the player is trying to win. Indeed, if nobody ever tried to win a given game then plausibly there would be no game practice and hence no games of that type. Moreover, there would be no obvious point to having competitive games if we did not, in general, try to win.

So playing a competitive game paradigmatically involves pursuing a goal. Moreover, we tend to value games whose goals are, at least to some extent, difficult, though not too difficult. We relish the challenge afforded by a good game, and this is why we seek out "worthy opponents." On the other hand, an opponent who is so much stronger that we have no hope of winning makes the game seem somewhat possible. Still, pursuing relatively difficult goals seems like an important part of most competitive games. Here I think we can find one of the sources of the real tension between playing full-stop and playing a competitive game in earnest.

While it is certainly logically possible to pursue difficult goals while remaining playful, it is not easy. This is difficult because play full-stop should be understood in terms of doing something for the fun of it. ${ }^{4}$ This is not quite sufficient for play fullstop. I might ride a roller-coaster or see a film for the fun of it, but these are not paradigms of play full-stop. In addition, play is essentially active (riding a roller coaster is passive in the relevant sense) and unscripted. The latter condition picks up on the intuitive idea that play essentially involves an element of spontaneity. Each of these elements of playing full-stop separately explains why playing full-stop can be difficult to combine with playing a competitive game in earnest. ${ }^{5}$

Consider first the element of being unscripted. This picks up on the passage from Huizinga quoted above, where Huizinga was concerned that competitive games are incompatible with spontaneity and free-spiritedness, and that the professionalization of games makes this problem even more severe. There is something very plausible about this. Putting cheaters to one side, playing a game does inherently involve

\footnotetext{
${ }^{4}$ Here I differ from those, like Suits (see Suits 1977: 124), who defines play instead as essentially autotelic-done for its own sake. This approach implausibly entails that acting from moral duty or contemplating God for its own sake is a form of play and divorces play too sharply from the affective element - having fun.

${ }^{5}$ I develop this approach to the nature of play in more detail in Ridge In Progress.
} 
following strict rules-rules which in some sense "constitute" the game. Yet playing full-stop involves whimsy and spontaneity. Think again of a child frolicking on a hill; his activity hardly seems to be well understood in terms of rule-following. Instead, the child simply "goes with the flow" and enjoys himself. He might simply relish the feeling and smell of the grass and roll around in it "without a care in the world." Or he might pretend to be an elephant, such that his arm "becomes" the elephant's trunk, but in the next moment pretend to be a jet-plane when his arms "are the wings." In the latter case, the child might follow a "rule" that says to turn left by dipping his left arm down, but he is not bound by that rule in that he can drop it on a whim and instead pretend to be a steam engine or perhaps revert to simply frolicking without any particular form of pretence in mind. ${ }^{6}$

This is, in my view, a real source of the tension between playing full-stop and playing competitive games in earnest, but it is also one which is (a) easily exaggerated and (b) highly game-relative. It is easily exaggerated because nobody, apart from sociopaths, ever behaves in a way that is entirely unconstrained by rules. The moral rules against murder, rape, stealing, lying etc. still constrain any decent person even as they are paradigms of playfulness. You don't have to be the Joker (of Batman fame) to be playful. Granted, for most decent people, the impulse to murder or assault their playmate (e.g.) would simply not occur to them, but that does not spoil the point. Such immoral behaviour would not occur to decent people in part precisely because they have so deeply internalized the corresponding moral rules; the moral rules thereby indirectly constrain their behaviour by limiting their deliberative field. Norms of etiquette, professional role norms and legal norms all typically constrain our behaviour even as we engage in behaviour that would normally be classified without hesitation as play full-stop. This is not to deny that there is still a tension, of course. The point instead is that we have a spectrum. Playfulness comes in degrees, and one element in the array of features that determines an activity's level of playfulness is how spontaneous and free of any prior rule or "script" it is. We are never completely free of the constraint of norms, so the mere fact that playing a game involves rule-following need not preclude our being playful any more than moral decency does.

Still, a tension can still arise here since games limit our spontaneity, thus at least reducing our level of playfulness. However, the extent to which this tension arises is highly game-relative. Some games leave almost no discretion for the players. Very simply children's games like Chutes \& Ladders and Candyland are like this. The rules of the game very strictly determine what moves one must make. Even here there is room for a kind of very minimal freedom and spontaneity, though. Although the rules determine that I move my playing piece to a given square, I can do this in a variety of ways-slowly or quickly, dramatically or prosaically, happily or begrudgingly, etc. Fortunately, though, not all games constrain us to this extent. In fact, these games are suitable only for very young children precisely because they leave players with so little discretion. Good games typically are challenging because

\footnotetext{
6 Thanks to an anonymous referee for drawing me out on this point, and for some of the examples used in the text.
} 
they offer opportunities for interestingly difficult choices. Chess, for example, has very strict rules for how the pieces move, but on each turn a player typically has many moves to choose from, not to mention choices to make about how much time to spend on a given move, etc. To be a good chess player one also needs to be very imaginative and good at "playing with ideas"-experimenting with odd-looking moves, "playing around with the move order," etc. Similar things can plausibly be said about countless other games-poker, Go, Scrabble, Hide \& Seek, Charades. It is not hard to see how the extent to which games reduces scope for discretion and spontaneity is highly game-relative.

Furthermore, we can understand the role of spontaneity in our concept of play in a slightly different way, and understanding it in this way opens up even more interesting ways in which complex strategy games like chess are amenable to playfulness. Rather than defining play full-stop in terms of the actual degree of spontaneity, we might instead plausibly define it in terms of one's behaviour manifesting a feeling of freedom from certain everyday constraints. This phenomenological conception of the element of spontaneity is not hard to find in many games. In fact, they often seem tailor made for it. Strategic games involve not only constitutive rules ("bishops move diagonally") but also strategic maxims ("a knight on the rim is dim"). The latter, though, do not hold universally, and part of being a good player is having the imagination and playfulness to find opportunities to break them successfully. Indeed, a recent strategic manual was written on just this theme, Neil McDonald's Break the Rules! (McDonald 2012), including such chapters as "The Anarchist of the Chessboard." For seasoned chess players, the strategic rules are deeply ingrained, though, so there is something exhilarating about breaking them, particularly when doing so actually is the best move and yields an advantage on the board. There is something mischievous about taking on tripled pawns or sacrificing a piece for unclear compensation, and for most chess players there is an exhilarating sense of freedom and spontaneity to be found in mischievously breaking the strategic rules in this way. This is why famous sacrificial players like Mikhail Tal are revered and at the same time seen as "impish." Insofar as playfulness involves a feeling of spontaneity, the fact that such strategic games have strategic rules built into their very fabric such that (a) the game encourages one to internalize those norms, but (b) it also incentivizes playfully looking for the exceptions and impishly taking advantage of them when the opportunity arises.

Nor is this the only way in which games can provide an exhilarating feeling of freedom from rules which normally constrain the player. Whereas chess offers opportunity for a sense of freedom juxtaposed with norms internal to that very game, other games seem designed to offer us a sort of "break" from some of the rules of conventional morality (Cf. Nguyen 2017). Poker, for example, allows players a break from the moral norm prohibiting deception, as do many other bluffing games. Monopoly valorises a kind of cutthroat competition in driving others bankrupt which decent people would find distasteful in the real world. Much more could be said about all of this, but my tentative conclusion is that the tension with playing competitive games arising from the element of spontaneity in play full- 
stop is easily exaggerated and highly game-relative. At any rate, this sort of gamerelative tension with playfulness is not my main focus in this essay. ${ }^{7}$

What, though, about the tension arising out of doing something for the fun of it and the intensity of the earnest competitor? Here I think things are more interesting. To get clear on this second source of the tension we need clarify what it is to do something "for the fun of it." It is neither necessary nor sufficient for doing something "for the fun of it" in my sense that one self-consciously sets oneself the aim of having some fun, judges that a given activity will generate fun, and engages in that activity for that reason. This caricatured Kantian view of doing something for the fun of it is, implausibly, compatible with the agent having no fun at all. Someone in a deep funk, psychologically incapable of enjoying themselves, might adopt and act on such a Kantian maxim, yet have no fun. Ebeneezer Scrooge going through the motions of "playing with a top" but clearly befuddled and not enjoying the process is not a paradigm of playfulness. Moreover, it is doubtful that young children or other animals self-consciously aim at having fun, but they are paradigms of playfulness. Instead, doing something "for the fun of it" as it figures in the definition of 'play' should be understood in terms of (1) the behaviour being fun, and (2) it's being fun functioning to reinforce the behaviour. Playing in this sense can be liberating and exhilarating precisely because it allows us to be free of any sort of external constraints, and not to be bound by any particular rule or set of rules.

How, then is doing something for the fun of it in this sense in tension with the pursuit of difficult goals? Here we must first say something about the nature of fun-itself a topic neglected by philosophers (and psychologists). Having fun is a positive experience, and it is tempting to define fun simply as enjoyment. Although 'fun' is probably sometimes used to mean something as broad as 'enjoyment', that is too broad to capture the core meaning of 'fun'. It would not be odd to say that you enjoyed a stunning performance of a tragedy like Romeo and Juliet, but it would be weird to say it was "fun." One clue is that etymologically 'fun' is the source of 'funny'.; 'fun' is derived from the Middle English word for 'fool' (Bogost 2016: 77). Perhaps unsurprisingly, some dictionaries include 'something that would be amusing' as one of the meanings of 'fun'. ${ }^{8}$ Although amusement is one form of fun, it does not exhaust the genus. Riding a roller coaster can be fun, but it is not typically amusing in the sense that a good joke is amusing (their presence at "amusement parks" notwithstanding). In an interesting discussion of the role of fun in play, Spinka, Newberry and Bekoff characterize fun as having 3 distinct phenomenological elements: (a) excitement, (b) pleasurableness, and (c) being

\footnotetext{
7 Yet another complication here is that 'play' can refer to play qua make-believe, which is not obviously the same as playing full-stop, though the two are plausibly compatible. In this sense, 'play' is what Geach would call an "attributive" modifier. When dogs are play-fighting, they are not actually fighting. This sense of 'play' is relevant since many games involve an element of pretense, most obviously role-playing games, but even strategic games like chess can be played in the frame of mind of someone who fantasizes about military strategy and conflict (even more so games like Risk).

8 (http://www.dictionary.com/browse/fun?s=t).
} 
relaxed (Spinka et al. 2001: 144). ${ }^{9}$ Prima facie there is a tension between "excitement" and "being relaxed." Spinka et al. are well aware of this tension but suggest that it can be resolved. The idea seems to be that one is "relaxed" in the sense that at some level one realizes the situation is not actually dangerous, even if it may superficially appear to be. Being relaxed in this sense is compatible with being excited or even thrilled by the experiences themselves. Perhaps "relaxed" is not quite the right concept, though. Being excited is a form of arousal and relaxation seems like the opposite of arousal. It would be better to replace "being relaxed" in their definition with a purely negative condition-something like "not anxious." One can be aroused in a broadly positive way without being nervous or fearful. Think again about someone who has fun by riding a roller coaster. The fun would be spoiled if they were scared to death, as some people are. The absence of anxiety in conjunction with a kind of pleasurable excitement seems to be closer to capturing the essence of fun.

This - the absence of anxiety and stress as essential to doing something for the fun of it- provides the key to understanding the real tension between playing fullstop and earnest competition. It is natural for human beings to feel anxious when something they value and care about is in jeopardy and their choices will determine whether everything turns out OK. Taking on a tough opponent in a game you care about can very easily produce stress and anxiety. If you have trained and worked very hard for the game, then the tendency to feel anxious will be even greater. Serious competitors invest a lot of themselves in those games. Michael Novak nicely articulates how a loss can threaten a competitor's self-esteem:

No use saying, 'It's only a game.' It doesn't feel like a game. The anguish and depression that seize one's psyche in defeat are far deeper than a mere comparative failure-deeper than the recognition of the opponent's superiority...A game tests, somehow, one's entire life. It tests one's standing with fortune and the gods. Defeat is too like death. (Novak 1976: 47)

This tension, while real, falls short of the logical contradiction that theorists like Kohn argue exists between play full-stop and competitive games. Indeed, one way to become better at many games is to learn how to be "cool under fire." Meditation and mindfulness are commonly suggested methods. This psychological tension might also be enough to make the normative critique of competitive games pressed by Huizinga, Kohn and others compelling. Apart from those few who play games professionally, why should we subject ourselves to such stress and anxiety? Most people's lives are already filled to the brim with stress and anxiety. Playing games should provide a diversion from these. Are we such masochists?

\footnotetext{
${ }^{9}$ In that paper they do not define play in terms of having fun, though but instead characterize play in essentially functional terms. Having fun on their view is simply a characteristic aspect of a behavioural pattern which is more fundamentally understood in terms of its function-helping the animal prepare for the unexpected. I discuss functional approaches below (in Sect. 4).
} 


\section{Ludic psychology}

To get a better sense of the tractability of the tension between playing full-stop and playing a competitive game, we must first clarify some issues in what might usefully be called "ludic psychology" - the psychology of playing games. Recall that on Suits' influential account, to play a game one must adopt the "lusory attitude" accept the rules constitutive of the game to pursue its constitutive aim.

What does this-the necessity of the lusory attitude for paradigmatic game play-tell us about the tension between playing a competitive game and playing full-stop? By itself, perhaps not much. However, when combined with certain influential theses about what it is to will an end it may tell us a lot. In particular, the thesis that to will an end is, in part, to see that end as good is relevant. This is one version of the broader idea that actions are performed "under the guise of the good." Kant provides a clear statement:

It is an old formula of the schools: Nihil appetimus nisi sub ratione boni; Nihil aversamur nisi sub ratione mali...the above quoted psychological proposition is at least very doubtful if it is translated; "we desire nothing except with a view to our weal or woe"; on the other hand, if we render it thus: "under the direction of reason we desire nothing except so far as we esteem it good or evil," it is indubitably certain, and at the same time quite clearly expressed. (Kant 1956: 59-60)

Many modern Kantians endorse this thesis:

It is internal to volition itself: in taking something as the object of one's will (that is, in adopting it as an end), one claims it to be good. (Ergstrom 1992: 760) If the agent did not believe the end or interest worth pursuing and the proposed plan of action the best strategy, all things considered, for attaining the desired end, there would be no reason to adopt the maxim.. ...rational agents...cannot adopt maxims without taking them to be...justified. (Allison 1990: 91)

We do not see what an agent wills until we see her action and end in the way she sees them as good. (Herman 1993: 221)

$\mathrm{He} / \mathrm{Kant} /$ started from the fact that whenever we make a choice we must regard its object as good. (Korsgaard 1996a: 122)

A rational action must be done with reference to an end that is good. (Korsgaard 1996b: 120-121)

Kant thinks that when we set an end for ourselves, and consequently regard it as good, we thereby regard it as something of value universally for all rational beings. (Wood 1999: 127)

The idea is also famously found in Plato, albeit in a different metaethical framework:

No one goes willingly toward the bad or what he believes to be bad; neither is it in human nature, so it seems, to want to go toward what one believes to be bad instead of to the good (Protagoras, Plato 1997: 358c6-d2) 
Suppose this Kantian/Platonist thesis is correct. It follows that when someone plays a competitive game, they deem winning good. Goodness can be realized in many ways, though. How does someone who plays a competitive game characteristically view winning as good? In principle, there need be no single answer. Different people value winning for different reasons, and different games are associated with different values. The typical poker player values winning because for financial rewards; not so with casual ping-pong. Some people value winning because it brings them social capital.

Clearly, we should be pluralists here. Still, one form of value stands out as especially paradigmatic, at least for competitive games based on skill: achievement. ${ }^{10}$ In fact, some of the most important discussions of the value of playing games have emphasized that games are effectively tailor-made vehicles for achievement. Both Thomas Hurka and Gwen Bradford have emphasized this point. On Hurka's account, achievements are activities which deliberately achieve a goal by overcoming some difficulty, and the greater the difficulty, the greater the achievement. Someone who excels in a game overcomes the challenges posed by the inefficiency imposed by the constitutive rules to achieve the prelusory goal thereby deliberately achieves a goal by overcoming some difficulty. Therefore, excellence in games entails achievement. Hurka agrees with those philosophers who hold that achievement is a non-instrumental value, and so concludes that excellence in games is non-instrumentally good. Moreover, this is no accident. As Bradford puts it in her landmark discussion, "Games are special in that their very structure has something very close to the central elements of achievement built right in." (Bradford 2015: 183)

There is some controversy over whether overcoming difficulties is sufficient for achievement. An obvious problem case is what we might tendentiously call "evil achievements" - tendentiously because whether they are achievements is part of what is at issue. Bradford argues that there can indeed be evil achievements, and that we are reluctant to call them achievements because we reserve the term for achievements of great value (Bradford 2015: 24; see also Bradford 2013). Strictly speaking, even walking your dog is an achievement, but not much of one. She argues that for the same reason we would find it misleading to refer to evil achievements as such. Another issue is whether achievements can have utterly banal ends, such as counting blades of grass efficiently. ${ }^{11}$ Fortunately, we need not resolve these broader issues here. My aim in this section is to explore the characteristic psychology of someone who plays a competitive game. Since my interest here is not

\footnotetext{
${ }^{10}$ I here put to one side games of pure chance. Gambling, of course, does indeed introduce an element of anxiety and stress, at least for those gambling with money whose loss will be painful. In this case, the solution is simply not to gamble with more than you can comfortably lose.

11 Tasioulas argues that achievements require some "framing value," and uses the example of counting blades of grass to make the point in Tasioulas (2006). I discuss these issues in Ridge (Forthcoming), where I argue that Tasioulas has a good point, but he either confuses what it takes for something to count as an achievement with what it takes for an achievement to be valuable or presumes without argument that achievements by definition are valuable (a presumption I argue is mistaken). The further details should not matter to the main lines of argument in the text here, though.
} 
in the ultimate truth about what is good about winning, but in ludic psychology, we can simply allow that players will have different views about this.

It is not hard to see how on this conception of the ludic psychology the competitor will be prone to anxiety which undermines playfulness. Someone who values winning as constitutive of achievement will, if they are serious about the game in question, tend to invest their self-esteem in winning. In the mind of such a player, winning is the natural outcome of skill, hard work, concentration and other virtues. Losing, on the other hand, is a sign of incompetence, laziness, distraction and other vices. Having your self-esteem on the line in this way is not conducive to playing full-stop, but instead naturally fosters anxiety and stress. Henry Russell Sanders, then the football coach at UCLA, famously remarked, "Winning isn't everything; it's the only thing." This attitude is no recipe for relaxed playfulness.

Fortunately, the almost comically hyper-competitive attitude encapsulated in Sanders' quip is not the only way to play a competitive game. In fact, it seems possible to play a game without valuing winning at all, but instead valuing the activity. Thi Nguyen makes this point effectively with what he calls "stupid games." Stupid games are (a) fun only if you try to win, but (b) the best is when you fail. Under the heading of "stupid games" we find not only many drinking games, but also Twister and Bag on Your Head. In Bag on Your Head, everybody puts a brown paper grocery bag on their head and then tries to take the bags off other people's heads while stumbling blindly around the room. Once the bag is taken off your own head you are eliminated. Eventually there is only one person stumbling blindly around the room with a bag on her head while everyone else watches, trying to supress laughter. That last person is the winner, but the best part of the game is getting to watch that person stumble about, so the real value of the game is found in losing. Nonetheless, the game only works if everyone tries to win. ${ }^{12}$ What stupid games demonstrate is that it is possible to play a competitive game without seeing any value in winning. Still, one tries one's best to win; otherwise the game does not work.

This very simple point provides an effective counter-example to the Kantian/ Platonic thesis that to will an end one must take that end to be valuable in some way. Stupid games are ones in which the players manifestly try to win, and so will winning as an end, but where they characteristically do not take winning to be valuable. ${ }^{13}$ Nguyen sometimes calls this a motivational "two-step": we adopt an end [first step], but not because we deem that end good in some way, but instead because adopting the end allows us to engage in a valued activity [second step]. In Bag On Your Head, a player will take it to be good that someone wins, but from

\footnotetext{
12 Nguyen (2019).

13 One might object that those playing a stupid game are not really trying to win but rather just "horsing around," and that this therefore sheds no light on the "guise of the good" thesis. I admit that this might be an apt description of some instances of some stupid games. All I need, though, to provide a counterexample to the guise of the good thesis is one merely possible case, since that thesis is meant to express a necessary truth. It seems clear to me that it is at least possible for someone to play a game like Twister or "Bag on Your Head" by trying to achieve its constitutive aims-by trying to win-and that is all that the argument in the text requires. Thanks to an anonymous referee for drawing me out on this point.
} 
their own perspective it is not best if they win-the real fun is had by the losers who get to watch the "winner" wander around the room, etc. Even more clearly in Twister one does not need to take it to be good that one put one's foot on the red circle (e.g.). Of course, a hyper-competitive person could play these games to generate achievements, but that would not be in the spirit of these games; imagine someone training to become a professional-level Twister player or a world-class Bag On Your Head player. Moreover, all we need to provide a counter-example to the Kantian/Platonic thesis that to will an end is to take it to be good is that it is at least possible to will an end without taking it to be good. So long it is as much as possible to play Bag on Your Head without taking winning to be good in any way, the Kantian/Platonic thesis is in trouble. A nice feature of these counter-example is that they do not require the attribution of any obvious practical irrationality to the agent. This stands in contrast to the more commonly used counter-examples, which ask us to evaluate the possibility of people pursuing ends they take to be either worthless or downright bad, but without any further backstory that makes this pursuit rational in some broader sense. With stupid games, the inversion of means and ends makes the actions perfectly intelligible and practically rational without requiring that the agent takes the end to be good. ${ }^{14}$

Does this mean that the ancient debate over whether intentional action is always performed "under the guise of the good" is somehow settled by the possibility of Stupid Games? No. The possibility of such games refutes only the Kantian/Platonic thesis that to will and end is to view that end as good. However, this reveals not that intentional action need not be performed under the "guise of the good," but that we must be more careful in how we understand that thesis. Those sympathetic to this thesis should understand it as asserting not that the end one wills must be seen as good, but that the action one intends to perform in its pursuit must be seen as good. ${ }^{15}$ Pretty clearly, stupid games provide no leverage against this thesis. The activity of playing these games is still seen as good by the players. It is good, though, not because it brings with it the possibility of winning. Instead, it is good because trying to win leads to certain other goods. Nguyen quite rightly emphasizes that such games highlight a certain easily overlooked fluidity in our agency.

On my preferred reading of Nguyen, he thinks it is possible to engage in striving play without ever judging that winning is actually good. On, this reading, the ludic sage wills winning as an end not because, in their view, winning is good, but because in their view willing winning as an end it is good in virtue of the activity it makes possible. However, Nguyen's discussion of "layered agency" and the way in which the striving player cares passionately about winning while they are engaged

\footnotetext{
14 Although I shall not pursue this here, they also undermine the idea that desires for states of affairs can never be rational in virtue of what Parfit called "state-given reasons" but must instead be based on objectgiven reasons.

15 This reformulation does, however, arguably have substantial implications. Arguably, this shift from the value of the end to the value of the activity in service of that end undermines certain "constituvist" arguments, most notably Christine Korsgaard's Kantian "regress" argument for the value of humanity as an end (see Korsgaard 1996a). I lack the space to develop this idea here, though; I discuss Korsgaard's argument in Ridge (2005a, b, c).
} 
with the game suggests another interpretation of his view. As he at one point puts it, the striving player "temporarily acquires an interest in winning for the sake of the struggle." (Nguyen 2019: 428) This suggests a view on which the striving player embodies a form of disunified agency, with the reflective agent (the one not engaged in game play, but thinking about why they play the game in a cool hour, e.g.) not judging winning to be valuable at all, and the playing agent judging that winning is valuable, and putting those more subtle thoughts about what trying to win makes possible out of their mind. Indeed, it is crucial for Nguyen that we must temporarily forget about the real reasons we are playing the game, as that would be distracting. Understood in this way, Nguyen's conception of striving play does not offer any counter-example to the guise of the good thesis. ${ }^{16}$

In a way, which of these interpretations is the right reading of Nguyen is not so important to my purposes here. My immediate point is that there is a plausible conception of striving play strongly suggested by Nguyen's work, and that conception undermines some versions of the guise of the good thesis. If that conception was not precisely the one Nguyen intended, that does not spoil my point so long as I can successfully argue that the conception I prefer is indeed a plausible one. My broader negative point in this paper concerns how realistic Nguyen's resolution of the tension between playing full-stop and playing a competitive game in earnest is. When I make that broader point below, though, I will return to the issue raised by this rival interpretation and argue that my objection is sound on either of the two interpretations of his view. The dialectic does, however, mean that for my more immediate purposes I need to argue that the conception of striving play I have extracted from Nguyen's work is indeed a plausible one. Otherwise I will have shown only that a potentially implausible and inferior conception of striving play would provide a counter-example to certain versions of the guise of the good thesis. Happily, I can do this while at the same time arguing that it is also a plausible reading of Nguyen's actual view. This is because the reasons the conception I favour is a more plausible one also provide reasons of charity to interpret Nguyen in this way.

The first thing to note is the potential for slippage between (a) being motivated by winning and (b) judging that winning is good. The possibility of weakness of will reminds us that these can come apart; we can be motivated to do things we know are bad and should not do. It is very clear that on Nguyen's view when we adopt a form of sub-agency to play a game, we are motivated by winning; that is a crucial part of the story. However, it is not at all clear that he needs or endorses the thesis that we must make the normative judgment that winning is good to engage in striving play. In fact, he consistently puts the point in motivational terms rather than in terms of any kind of normative judgment. In the passage quoted above, he speaks of "acquiring an interest," for example. Elsewhere he talks about coming to "take on...temporary ends" and inducing ourselves to "care about" an arbitrary goal (Nguyen 2019: 425). Here again, the characterization is motivational, rather than in terms of normative judgment. In a more detailed discussion of the phenomenology

$\overline{16}$ Thanks to an anonymous referee for drawing me out on this point. 
of striving play, Nguyen again focuses on motivation in ways that are much more suggestive of desire than normative judgment:

During the game, if we have any competitive spirit at all, we acquire a hearty interest in the green tokens, to the point where a differential in collected tokens may inspire armpit sweats, jitters and a surge of adrenaline at the proposed last-ditch plan...(Ngueyn 2019: 436)

The closest Nguyen comes to talk of normative judgment is when he remarks that to engage in striving play one must submerge oneself in an agency that "values winning" (Ngueyn 2019: 440). However there is a useful distinction to be drawn between valuing winning and judging that winning is valuable. In one useful sense, anything you prefer or care about is something you value, but you might in this sense value something while not judging that it is, in fact, valuable. Frankfurt's famous unwilling heroin addict in one sense values taking heroin, but by hypothesis does not think taking it is valuable.

Granting that Nguyen is not himself committed to the view that when engaged in striving play we deem winning valuable, we can ask whether he should have taken that view nonetheless. Why should we interpret his examples as demonstrating the possibility of willing an end without valuing it, rather than as simply being instances of layered agencies in which the sub-agent both wills the end and values it? I cannot provide a detailed answer to this question here, but a crucial part of the answer is that judging something valuable constitutively involves a disposition, if pressed, to give reasons for thinking it is valuable. Obviously I cannot give a proper argument for this thesis about the nature of normative judgment here, but it is fairly orthodox to think of belief in general as a functional state which constitutively aims at the truth, and so as bound up with dispositions to provide reasons for thinking its content is true. Those playing stupid games like Twister and Bag on Your Head will not typically have this disposition. If we interrupt the flow of the game and ask them why it is good to win, if they are thinking clearly they will not only not give reasons winning is good they will deny that it is good and explain that what is good is trying to win but that trying to win is good only because of the inevitability of someone failing, which is what is really valuable in those games. Therefore even when submerged in the sub-agency of a player, we do not judge that winning is good, or anyway we need not. Our thought is simply "I really want to win!" rather than "Winning is valuable." Granted, when playing the game we also must put the thought that winning is worthless out of our mind, but there is a crucial difference between simply not thinking about whether winning is good (which is an essential part of the story), on the one hand, and coming to think that winning is good (which is not).

One might wonder on this reading why Nguyen repeatedly emphasizes that the striving player embodies a kind of disunified agency. Here I think the key is to distinguish disunity from incoherence. It is sufficient for disunity that the agent "walls off" certain considerations, taking them out of his deliberative field; that is in itself a kind of lack of unity, and my reading secures this. This is rather different from having the reflective agent believe that $\mathrm{p}$ and the striving sub-agent believe that not-p. That would, in my view, be a form of incoherent agency because the sub- 
agent is not literally another agent. One way to see this is to think about agency as a forensic notion. If someone committed a crime while engaging in striving play (think of e.g. The Hunger Games sorts of games) we would not allow them to evade criminal liability on the grounds that "that wasn't me, officer, that was the striving agent that temporarily inhabited this body-I'm the reflective one!" Moreover, Nguyen himself is fairly clear on this point, explaining that he prefers to call the phenomenon "layered agency" for precisely this reason:

This is not, however, best described as a change in our agency or even the temporary wholesale adoption of a new agency. Rather, it is best described as layered agency - as the creation of a temporary agency nested within our overall agency. This is because the ends of our primary agency continue to regulate the maintenance of the temporary gaming agency, though in and interestingly distanced way. When I play a game of Super Mario Kart, I adopt a temporary agency that wishes to win the race...my immersion within that temporary agency is still regulated by the interests of my overall agency. I intermittently step back from the temporary agency and ask myself: is this fun? Are we having a good time, or is this game so terrible that we should just give it up and play something else? (Nguyen 2019: 443)

Given that we have nested agency, it would be better to avoid attributing outright contradictory beliefs. We can disunity by "walling off" certain thoughts without incoherence. In my view, this interpretation is both faithful to the text and more plausible than one on which the striving player believes something which contradicts the belief of the reflective agency (both of which are part of the same overarching agency).

\section{A residual tension?}

Insofar as it is possible to will an end without taking it to be good, it follows that someone could play a game without taking winning to be good. This possibility goes well beyond stupid games; they simply provide an especially clear and vivid demonstration of this possibility. Even if all action is performed under the "guise of the good," there are many ways in which people can take playing games, including competitive games, to be good independently of winning. First, people are not always so driven by achievement. People play competitive games for all sorts of reasons: to socialize (pensioners playing Bingo), for financial gain (professional athletes, professional gamblers), for their health (most sports), for excitement (gambling), for amusement (drinking games, Bag on Your Head), to distract them from their troubles (most games in some contexts), for the aesthetic value of the game (an elegant dive), to be part of a large community and ongoing practice, and many other reasons as well. Second, even those who play games for the sake of achievement should not be so focused on winning. Winning is neither necessary nor sufficient for achievement. It is not necessary since it is an achievement to play the game well even if you lose. Nor is winning sufficient for achievement, or at any rate 
for an achievement worth being proud of; defeating a much weaker opponent is nothing to write home about (Cf. Bradford 2015).

It might therefore seem that the tension between playing a competitive game and playing full-stop can be resolved straightforwardly. To play full-stop while playing a game, one must simply attach value to the process of playing the game and not to the end (winning). In fact, this is precisely what Nguyen suggests we should do, though his interest is not so much on the possibility of combining play full-stop with playing competitive games as on realizing a certain aesthetic experience and on how well-designed games can transform anti-social impulses into something pro-social (Nguyen 2017). Still, it seems a good antidote. Recall that the source of the tension was that the stress and anxiety associated with needing to win precludes enjoying the process. If the player does not deem winning valuable, then this stress and anxiety should dissipate.

This would be a hollow victory if the point did not apply to those who play competitive games as a vehicle for achievement. Here it is crucial to recall that winning is neither necessary nor sufficient for achievement. Playing well, is an achievement, and one the player can value wholeheartedly without anxiety about winning. Win, lose or draw, if one plays one's best then that is already an achievement. Of course, if one's achievement depends on playing well, that can itself become a source of stress and anxiety. Instead of worrying about the result, one can become stressed and anxious about the quality of one's play. One might, therefore, worry that Nguyen's "motivational two-step" only moves the bump in the rug.

In my view, the proposed motivational two-step does "move the bump in the rug," but it does not just move it. It also shrinks it. When someone is focused on a game's outcome, they are easily distracted from the process of playing. This not only predictably leads them to play worse, it also renders them unable to appreciate what is right in front of them-to have fun with the game, explore the space of possibilities they currently face and enjoy themselves. If, on the other hand, someone focuses on playing well then it is more likely that they will stay focused on the here and now-on finding the best move. A focus on playing well lends itself to "losing oneself in the position," appreciating the nuances of the position, the elegance of certain moves one might make, surprising ideas hidden in the position, one's opponent's ideas, and so on. It is this losing of oneself the here and now of the game that lends itself to having fun-to appreciating the beauty or even the humour of various possible moves. As Ian Bogost argues, fun arises out of the right sort of total engagement with the here and now:

Fun isn't a distraction or an escape from the world, but an even deeper and more committed engagement with it. The golfer who fails to engage with the various figures of the course and its related materials... is likely to have far less fun than the player who has, through practice and attention, found reason to address those conditions as part of the play experience. (Bogost 2016: 81)

It is in this "worldful" attitude, which Bogost contrast with the more trendy "mindfulness" that enables us to have fun. When things go well, we can even achieve what Mihaly Csizszentmihalyi calls a "flow state" by staying focused in 
this way, though this requires that some further conditions are met-we typically must be pressing ourselves just beyond the edge of our abilities and find ourselves "in the zone" reaching a kind of peak performance (Csizszentmihalyi 1990). Csizszentmihalyi repeatedly emphasizes that a deep level of engagement and "losing oneself" in the task at hand is an essential element in achieving flow states. In sum, while focusing on playing well can still lead to anxiety, it is less likely to have this consequence than a focus on the result.

My concern with Nguyen's motivational two-step is not that it would not help resolve the tension I have been exploring here. My concern is rather how realistic this two-step is, especially for what we might call "earnest competitors"competitors who are serious about doing well at the game they cherish and who devote substantial time and energy to improving. Even for a competitor who is not earnest in this sense-someone simply having a casual game of Settlers of Catan with his friends or family-the motivational profile Nguyen proposes will be challenging. Granted, willing an end does not entail that you take that end to be good in any way; one must at most take acting in pursuit of that end to be good. Nonetheless, there is at least a strong tendency to see one's ends as good in some way. As rational agents, we are disposed to try to make sense of our actions. When we are trying hard to win the game we are playing it will therefore be very natural to take winning to be a worthwhile goal. In our more reflective moments we may sometimes be able to take a step back and remind ourselves that we pursue victory not because it is itself good, but because its pursuit is. Depending on how earnest one is in pursuing the end, managing this level of detachment even in one's more reflective moments is likely to be very challenging. In the "heat of battle," though, this more circuitous perspective will be even more elusive for most people.

Furthermore, if what we value is achievement then winning often will be good. Granted, winning is not logically sufficient for achievement worth caring about. In a given context, though, when facing a tough opponent one can only beat by playing the top of one's game, winning plausibly will partly constitute one's achievement. Or, at the very least, winning will be excellent evidence that one has achieved something in such circumstances, and losing will be excellent evidence that one has failed. Thus, even for someone who fully appreciates the possibility of achievement in a game without winning in general, winning can rightly be seen to be important in a given context of play. Moreover, a focus on "playing well" does not entirely help distract one from thoughts of winning. For "playing well" just is playing in ways conducive to winning. To focus on playing well can, therefore, easily lead one back to thoughts of winning, which in turn can generate the anxiety that a focus on playing well was meant to help block.

Finally, I have so far assumed something like full rationality, but this is also not realistic. When someone works hard to pursue some end, it is all too easy to fetishize that end. This is easily illustrated with currency. Apparently, economics professors sometimes tear a dollar bill in front of their class to make a point about 
how we treat currency as almost sacred. ${ }^{17}$ Inevitably, some students gasp and find themselves shocked by this behaviour, even though they should know that the banknote is not good in itself-nor, indeed very valuable instrumentally for that matter-one dollar will not buy very much. Moreover, the same students would not be shocked if he had merely torn up a magazine which cost more than a dollar. If we can so easily fetishize and treat as sacred something like a one dollar bill, then how easily will earnest competitors come to fetishize winning?

What about the two readings of Nguyen discussed at the end of Sect. 2, though? So far my critique of Nguyen has implicitly focused on my preferred reading of his view. On that view, our striving agency cares about winning but does not judge that it is good. What if we loosened up on that view, though, and in spite of my arguments in Sect. 2 read Nguyen's view as one on which the striving agent does indeed judge that winning is good, but the reflective agent judges that winning in itself is worthless, and it is only the process of good striving play that matters. That would indeed make Nguyen's view more realistic, but in my view the worry about realism persists. All the arguments just rehearsed are arguments that it is unrealistic for the earnest competitor not to judge that winning is good both in the heat of the moment and in their more reflective moments.

I therefore provisionally conclude that Nguyen's motivational two-step, while possible, does not provide a psychologically realistic strategy for navigating the tension between playing a game and playing full-stop. Suits' "lusory attitude" is multiply realizable, and Nguyen's motivational two-step provides one form it can, in principle take. However, for most of us, this form will be more of an illusory attitude than a lusory attitude we can take. We have, though, made progress. By combining Nguyen's ideas with some of the insights of Stoicism, we can craft a better strategy.

\section{The playful stoic}

What is unrealistic about Nguyen's motivational two-step is that we must deem victory worthless. However, something in the spirit of Nguyen's proposal is more realistic. Rather than assigning no value whatsoever to victory, the earnest gamer might assign far less value to winning than playing well. In the terms of the trade, they might even assign lexical priority to playing well, such that all else being equal they would prefer to play well and lose than play poorly and win. This sort of ludic psychology will not be easy, of course, but it is considerably more realistic than assigning no value whatsoever to victory. Moreover, this perspective does seem to be one that many serious competitors at least strive to attain. Chuck Noll, the head coach of the Pittsburgh Steelers once remarked that he would "rather play well and

\footnotetext{
17 Apparently, this is illegal, though I do not think this is why students are viscerally shocked by it (many of them probably do not know it is illegal, for one thing).
} 
lose than play poorly." ${ }^{18}$ Reminding oneself that playing well is an achievement can help.

To take this attitude is to keep things in perspective, and one of the great insights of Stoicism is the importance of keeping things in perspective. A related Stoical idea is that one should concern oneself only with what is in one's control. As has often been noted, Stoicism anticipates the main idea of the "Serenity Prayer"19.

God grant me the serenity to accept the things I cannot change,

Courage to change the things I can,

And the wisdom to know the difference.

The idea that we must not become attached to things beyond our control, such that we will be upset or disappointed when those things do not go as we would prefer, is one of the most central ideas in the Stoic tradition. Worrying about things beyond our control is pointless, and only makes us suffer when these things do not go as we want them to go. Epictetus begins The Handbook ${ }^{20}$ with this remark:

Some things are up to us and some are not....if you think that only what is yours is yours, and that what is not your own is, just as it is, not your own, then no one will ever coerce you, no one will hinder you....and no one will harm you, because you will not be harmed at all (Epictetus 1983: 11)

He adds, "if you desire something that is not up to us then you are bound to be unfortunate." (Epictetus 1983: 12).

The Stoics took this idea to what some consider an extreme, even inhuman conclusion. In particular, many readers find this passage problematic:

If you are fond of a jug, then say 'I am fond of a jug!' For when it is broken you will not be upset. If you kiss your child or your wife, say that you are kissing a human being; for when it dies you will not be upset. (Epictetus 1983:

Whether this level of detachment is compatible with loving your child or wife is not obvious, so it is not hard to see how someone might find Epictetus' conclusion somewhat monstrous. Fortunately, I do not need to defend every aspect of Stoicism. Perhaps there are some goods, like love, which require a kind of attachment but which are valuable enough to be worth the suffering we inevitably face when we lose what we love. Still, unless some such important good is at stake, the Stoical idea that we should not become attached to things beyond our control is plausible.

\footnotetext{
18 https://books.google.co.uk/books?id=b2PMfwPrTG4C\&pg=PA139\&lpg=PA139\&dq=chuck +noll+\% 22play+well+and+lose $\% 22 \&$ source=bl\&ots=2qUEFmzyyu\&sig=ZFPB365uk9-8xfwP_ SeZXJo4v6g\&hl=en\&sa=X\&ved=0ahUKEwi87qrIsfTUAhUHDMAKHXu4DOAQ6AEILjAB\#v= onepage \&q=chuck $\% 20$ noll $\% 20 \% 22$ play $\% 20$ well $\% 20$ and $\% 201$ ose $\% 22 \& \mathrm{f}=$ false.

19 Cf. Pigliucci (2017: 30-31).

20 The Handbook was not written by Epictetus himself, but was instead based on his students' notes. In fact, 'Epictetus' was not even his real name, which is lost to history-he is so called because he was a slave for much of his life and 'Epictetus' means 'acquired' (Cf. Pigliucci 2017: 13).
} 
This weaker doctrine, which we might call "Stoicism light," is sufficient for present purposes.

A closely related Stoical idea which will be important for mitigating the tension between playing a competitive game and playing full-stop is the oxymoronic sounding category of the "preferred indifferent." For the Stoics, the only thing that is intrinsically valuable is our character - the virtues. In that sense, everything else, including things we typically think of as good, like health, friendship, longevity, fall into the category of the "indifferent." However, not all "indifferents" are created equal. Some indifferent things are "in accord with nature" and others are "against nature." It is rational to pursue indifferents which are "in accord with nature," but not rational to pursue indifferents which are "against nature"-or indifferents which are "absolute indifferents," like having an odd number of hair on your head, saythese are neither in accord with nature or against nature. Crucially, although it is rational to pursue the preferred indifferents, it is not rational for us to grow attached to them. Because they are not entirely within our control and such attachment will only lead to suffering when we cannot attain them. Epictetus illustrates this with the example of a banquet:

Remember, you must always behave as you do at a banquet. Something is passed around and comes by you: reach out your hand and politely take some. It goes by: do not hold back. It has not arrived yet: do not stretch your desire out toward it, but wait until it comes to you. In the same way toward your children, in the same way toward your wife, in the same way toward public office, in the same way toward wealth, and you will be fit to share a banquet with the gods. (Epictetus 1983: 15)

The preferred indifferents can be enjoyed when they are available, and it is rational to pursue them, but we must not become attached to them. We must remind ourselves that they are not up to us, and that becoming attached to them can only lead to dependence and suffering. Moreover, because the only thing that is necessary for a good life is virtue, we do not need these things to have a good life.

The Stoics explained the value of preferred indifferents in terms of what is "in accord with nature," and that is a rightly controversial aspect of their view. As many philosophers have plausibly argued, the fact that something is "natural" on any of a number of senses of 'natural' does not entail that it is good. Fortunately, we do not need to endorse the Stoical explanation of why preferred indifferents are choiceworthy. What matters for present purposes is the structure of the view-the idea that these goods can never be traded off for one's virtue or integrity. One's virtue thus has lexical priority. We can endorse this lexical priority thesis without deriving value from nature.

How do these Stoical ideas help mitigate the tension between playing a competitive game and playing full-stop? First, the idea of not becoming attached to things beyond your control has a clear application here. Playing well is within your control, so long as what counts as "playing well" is understood as relative to your abilities. I can play a good game of chess relative to my standard without playing well in some more objective sense. Whether you actually win the game, on the other hand, is not up to you. By playing well you maximize your chances of victory, all 
else being equal (sometimes poor play wins through a fluke, of course). Even so, you might play your best and be outplayed. A virtuous Stoic will, therefore, not become attached to victory. Instead your aim should simply be to play your best.

Second, the Stoical category of the "preferred indifferent" is useful in providing a more realistic approach to playful yet earnest competition. Recall that Nguyen's motivational "two-step" is, I argued in the previous section, unrealistic for most serious competitors because it entails attaching no value to victory. The playful Stoic, however, can treat victory like one of the dishes at the banquet Epictetus discussed. Victory can be enjoyed and even relished when it presents itself; it can be treated as a preferred indifferent. The playful Stoic can take joy in her victories. So long as she reminds herself that ultimately victory is not up to her, but only how well she plays, she can avoid the sort of attachment to victory that will lead to anxiety over the outcome. This, in turn, should make it easier to combine playing the game with playing full-stop, but in a way that involves considerably less cognitive dissonance than the sort of ludic psychology required by Nguyen's motivational two-step.

In fact, this point was not lost on the Stoics. Epictetus once put forward Socrates as a kind of Stoic sage, and compared his life to playing a game with a ball:

[Socrates] was like one playing with a ball. What then was the ball that he played with? Life, imprisonment, exile, taking poison, being deprived of his wife, leaving his children orphans. These were the things he played with, but none the less he played and tossed the ball with balance. So we ought to play the game, so to speak, with all possible care and skill, but treat the ball itself as indifferent. (Epictetus 2008: II.5)

Had the passage ended with 'but treat victory as indifferent' then this passage would have been perfect for my point. However, it seems clear that Epictetus would have endorsed this further sentiment too. The passage moreover, nicely suggests another lesson-that we can usefully treat life itself as a kind of game-so long as it is a game we play in the manner of a Stoic sage. Massimo Pigliucci provides a nice discussion of the Stoic's use of games as a model for life in chapter 5, "Playing Ball With Socrates" of his How To Be a Stoic:

...suppose that you are playing a tennis match or, more consequentially, being considered for a promotion at your job. The Stoic approach to both situations is the one counselled by Epictetus... while we naturally think our goal is to win the match, or get the promotion, those outcomes of course are not in our control...we need to make our goal something that actually is in our power and not even Fate can rob us of: to play the best match we can, regardless of outcome, or to put together the best promotion file we can.... (Pigliucci 2017: 213)

On the approach I am proposing, we do still have a motivational two-step, but just a different one from the one Nguyen discusses. On Nguyen's version, when I adopt the lusory attitude, I do so entirely for the sake of the activity that it makes possible, and I take victory to have no value in itself even as I make victory my end and strive to achieve it. On the Stoical approach I am suggesting, when I adopt the lusory 
attitude, I do so primarily for the sake of the activity it makes possible, but I can at the same time do so in part for the sake of victory so long as I treat victory as a merely preferred indifferent. This form of the lusory attitude is, in my view, less illusory than the one Nguyen proposes.

Even with this perspective, it will not always be easy to blend playing a competitive game in earnest with playing full-stop. In my view, there is a kind of dynamic tension between playing a competitive game in earnest and remaining playful and so playing full-stop. Bernard de Koven captures this dynamic tension nicely:

There is a very fine balance between play and game, between control and release, lightness and heaviness, concentration and spontaneity. The function of our play community is to maintain the balance... On the one hand we have the playing mind-innovative, magical, boundless. On the other is the gaming mind-concentrated, determined, intelligent... The balance between the playing mind and the gaming mind is never at equilibrium. There is a dynamic tension between these two-a dialog. Playing well means playing within that dialog." (de Koven 2013: 40-410)

Interestingly, we can make a virtue of necessity to help further ease the tension. The striving mind of the fierce competitor tends to crave achievement, and achievement plausibly just is overcoming difficulties. Precisely because it is difficult to maintain a playful attitude while working hard to win, it should be possible for the earnest competitor to find motivation to try harder to do so. If playing well is an achievement then managing to play well while not becoming too focused on the outcome is an even more impressive achievement!

I close this section with an important caveat. While the attitude of the "playful Stoic" provides a healthy way to access the values associated with many competitive games for many players, it is, in a sense, not universally valid. For example, the point of some games seems to be not so much "fun" in a fairly undifferentiated sense, but rather the "thrill" of the game. Poker is a nice example. Some people prefer poker with really money - and, indeed, enough real money that losing will "hurt," at least somewhat-because it gives them a kind of adrenaline rush. Although the achievement might in some sense be equally great if playing for "play money," for this kind of gambler that would be a pale imitation of the real thing. In this kind of case, the adrenaline rush may come only because the player is, indeed, somewhat anxious about the outcome. Insofar as that is the point of the activity, for that player, though, the more relaxed attitude of the playful Stoic would not be helpful. ${ }^{21}$ That being said, the scope of this point is easily exaggerated. Some poker players might enjoy the game equally or even more if they managed to conquer their anxiety and "keep their cool" at the table. Indeed, this might even be the key to a more lucrative poker career. As one of th first women to win a major poker championship put it, "Courage is the key to high stakes poker. You must treat

21 Thanks to an anonymous referee for pressing me on this point. 
the white chip simply as a white chip, whether it is worth just one nickel or one thousand dollars." (Seligman 2011: 101)

\section{Conclusion}

I have argued that the tension between playing full-stop and playing a competitive game in earnest is easily misunderstood but real. The tension does not amount to a logical contradiction, but a kind of psychological dissonance. Further articulating this tension revealed that playing games provide a kind of counter-example to the Kantian/Platonic idea that to will and end is to deem that end as good. This surprising corollary for action theory put us in a better position to see how best to resolve the tension between playing a competitive game in earnest and playing fullstop. One approach is suggested by Thi Nguyen's interesting "motivational twostep," but I argued that this approach ultimately is not realistic-at least not for most earnest competitors. We should instead turn to the Stoical tradition, where the ideas of not becoming attached to things beyond our control and the idea of a "preferred indifferent" help us maintain the kind of poise necessary for combining playing a competitive game in earnest with playing full-stop. Even with this more Stoical approach, combining these attitudes will not be trivial. However, precisely because it is a challenge, the sort of person who relishes competitive games, and who thus craves achievement, should be suitably motivated to work hard to achieve this healthier attitude. By doing so, she can add another achievement to her list.

Acknowledgements Thanks to Thi Nguyen, Matthew Chrisman, Guy Fletcher, Elinor Mason, Debbie Roberts, Chase Wren and the usual assorted cast of anonymous referees for helpful comments on earlier drafts.

Open Access This article is licensed under a Creative Commons Attribution 4.0 International License, which permits use, sharing, adaptation, distribution and reproduction in any medium or format, as long as you give appropriate credit to the original author(s) and the source, provide a link to the Creative Commons licence, and indicate if changes were made. The images or other third party material in this article are included in the article's Creative Commons licence, unless indicated otherwise in a credit line to the material. If material is not included in the article's Creative Commons licence and your intended use is not permitted by statutory regulation or exceeds the permitted use, you will need to obtain permission directly from the copyright holder. To view a copy of this licence, visit http:// creativecommons.org/licenses/by/4.0/.

\section{References}

Allison, H. (1990). Kant's theory of freedom. Cambridge: Cambridge University Press.

Bogost, I. (2016). Play anything. New York: Basic Books.

Bradford, G. (2013). Evil achievements and the principle of recursion. In M. Timmons (Ed.), Oxford studies in normative ethics (Vol. 4, pp. 79-97). Oxford: Oxford University Press.

Bradford, G. (2015). Achievement. Oxford: Oxford University Press.

Csikszentmihalyi, M. (1990). Flow. New York: Harper Collins.

de Koven, B. (2013). The well-played game: A Player's philosophy (pp. 40-41). Cambridge: MIT Press. 
Engstrom, S. (1992). The concept of the highest good in Kant's moral theory. Philosophy and Phenomenological Research, 52, 747-780.

Epictetus, (1983). The Handbook. Indianapolis: Hackett.

Epictetus, (2008). Discourses and selected writings. London: Penguin.

Herman, B. (1993). The practice of moral judgment. Cambridge: Harvard University Press.

Huizinga, J. (1949). Homo Ludens. London: Routledge and Kegan Paul.

Hurka, T. (2019). Suits on games: Slightly revised, slightly restricted. In Hurka (Ed.), Games, sports and play: Philosophical essays (pp. 13-32). Oxford: Oxford University Press.

Kant, I. (1956). Critique of practical reason (1788), trans. Lewis White Beck. Library of Liberal Arts.

Kohn, A. (1986). No contest: The case against competition. Boston: Houghton Mills.

Korsgaard, C. (1996a). The sources of normativity. Cambridge: Cambridge University Press.

Korsgaard, C. (1996b). Creating the Kingdom of ends. Cambridge: Cambridge University Press.

McDonald, N. (2012). Break the rules!. London: Gloucester Publishers, Everyman Chess.

Ngueyn, T. (2017). Competition as cooperation. Journal of the Philosophy of Sport, 44, 123-137.

Ngueyn, T. (2019). Games and the art of agency. Philosophical Review, 12, 423-462.

Novak, M. (1976). The joy of sports: End zones, bases, baskets, balls, and the consecration of the American spirit. New York: Basic Books.

Pesce, M. (2014). Contraludics. In Walz and Deterding (eds.) (pp. 107-111).

Pigliucci, M. (2017). How to Be a Stoic. Lodnon: Penguin.

Plato. (1997) Complete works. In J. Cooper \& D. S. Hutchinson (Eds.) Indianapolis: Hackett.

Ridge, M. (2005a). Why must we treat humanity with respect? European Journal of Analytic Philosophy, 2, 57-73.

Ridge, M. (2005b). How to play well with others. In Hurka (Ed.), Games, sports and play: Philosophical essays (pp. 74-98). Oxford: Oxford University Press.

Ridge, M. (2005). In Progress. Why So Serious? The nature and value of play.

Ridge, M. (Forthcoming). Games and the Good Life. Journal of Ethics and Social Philosophy.

Rowson, J. (2019). The moves that matter. London: Bloombsury.

Seligman, M. (2011). Flourish. London: Nicholas Brealey Publishing.

Spinka, M., Newberry, R., \& Bekoff, M. (2001). Mammalian play: Training for the unexpected. Quarterly Review of Biology., 76, 141-168.

Suits, B. (1977). Words on play. Journal of the Philosophy of Sport, 4, 117-131.

Suits, B. (1978). The grasshopper. Edinburgh: Scottish Academic Press.

Tasioulas, J. (2006). Games and the good II. In Proceedings of the Aristotelian Society (pp. 237-264).

Wood, A. (1999). Kant's ethical thought. Cambridge: Cambridge University Press.

Publisher's Note Springer Nature remains neutral with regard to jurisdictional claims in published maps and institutional affiliations. 